\title{
A influência dos sindicatos nos salários do setor sucroalcooleiro
}

\section{MÁRCIA AZANHA FERRAZ DIAS DE MORAES*}

The influence of labor unions on wage formation in the sugarcane sector. The aim of this paper is to identify the determinants of the income of the employees of the sugarcane sector, and also for the sugar and ethanol industries. Special attention is given to union's role. Earnings equations were estimated for these sectors and information on union's action were collected in a field research. In the regressions estimated, the coefficients of the following variables were significant and had the expected signs: (i) gender (ii) region, (iii) education, (iv) threshold effect of education, (v) membership to labor unions. It was verified the existence and also the influence of labor unions on wage formation

Keywords: mercado de trabalho; lavoura canavieira; sindicatos; equação de rendimento; indicadores sociais.

JEL Classification: J21; J43.

\section{INTRODUÇÃO}

O setor de açúcar e álcool nacional tem passado por profundas alterações nos anos recentes, ${ }^{1}$ com impactos sobre a organização setorial, estratégias empresariais e sobre o mercado de trabalho. Notadamente no estado de São Paulo, o cronograma para a extinção da queima da cana-de-açúcar como método de despalha, com consequente mecanização da colheita, ocasionará redução importante na demanda por empregados agrícolas.

\footnotetext{
* Professora da Escola Superior de Agricultura Luiz de Queirós, da Universidade de São Paulo. E-mail: mafdmora@esalq.usp.br. Pesquisa desenvolvida com auxílio do CNPq. Submetido: Outubro 2008; Aprovado: Janeiro 2010.

${ }^{1}$ Dentre as principais mudanças ocorridas citam-se a desregulamentação do setor sucroalcooleiro, ou seja, a drástica redução da intervenção estatal (ver Moraes, 2000, 2007b).
} 
A despeito dos avanços técnicos e ganhos de produtividade exibidos pela agroindústria canavieira desde a instalação do Proálcool, em meados da década de 1970, e das expectativas positivas de aumento da demanda pelo álcool combustível, é frequente o questionamento por parte da sociedade sobre as condições do seu mercado de trabalho, principalmente da lavoura de cana-de-açúcar.

Ademais, os países produtores de açúcar e concorrentes do Brasil argumentam que a competitividade nacional (o país tem o menor custo de produção de açúcar e de álcool do mundo) decorre de problemas ambientais e trabalhistas. Em que pese o exagero dos países concorrentes do Brasil, faz-se necessário um melhor entendimento do mercado de trabalho da agroindústria canavieira nacional.

A análise de indicadores socioeconômicos referentes aos empregados do setor de cana-de-açúcar, açúcar e álcool indica diferenças regionais importantes: enquanto na principal região produtora do Brasil, a Centro-Sul, os indicadores têm evoluído positivamente (aumento da formalização, redução do trabalho infantil, cumprimento dos acordos salariais estabelecidos nas negociações coletivas de trabalho) na região Norte-Nordeste a situação mostra-se relativamente pior, embora também tenham se verificado melhorias ao longo do tempo.

No que diz respeito aos salários dos empregados, foi observado que existem diferenças nos rendimentos dos trabalhadores das duas regiões produtoras, sendo que os empregados da região Centro-Sul recebem salários mais altos que os da região Norte-Nordeste.

Diversos autores analisam as diferenças salariais associadas às variáveis idade, sexo, escolaridade, grupos ocupacionais, posse prévia de propriedade e riqueza, dentre outras. No que se refere às negociações salariais na agroindústria canavieira, Moraes e Pessini (2004) salientam a atuação efetiva dos sindicatos de classe, patronais e de trabalhadores, no estado de São Paulo, o que poderia ser mais um fator para explicar as diferenças encontradas nos rendimentos dos empregados dos setores produtivos de cana-de-açúcar, etanol e açúcar.

A presente pesquisa objetiva apresentar os indicadores socioeconômicos dos empregados da agroindústria canavieira, bem como a identificação dos determinantes dos seus rendimentos, com ênfase na atuação sindical. Para tanto, utilizaram-se os dados da Pesquisa Nacional por Amostra de Domicílios (PNAD) dos anos de 1993 e 2006, para estimar equações de rendimento para os empregados do setor da cana-de-açúcar, e para a indústria do açúcar e do álcool, comparando as distintas regiões produtoras, Norte-Nordeste e Centro-Sul. Também foi realizada uma pesquisa de campo ${ }^{2}$ para verificar a existência e atuação dos sindicatos de classe nos estados de Pernambuco e Alagoas.

\footnotetext{
${ }^{2}$ A autora agradece o auxílio recebido do $\mathrm{CNPq}$ para a realização da pesquisa de campo.
} 


\section{REVISÃO DE LITERATURA}

Vários indicadores socioeconômicos da agroindústria canavieira - como grau de escolaridade, formalização do emprego, níveis salariais - apresentam-se melhores na Região Centro-Sul, e mais especificamente no Estado de São Paulo, em relação à região Norte-Nordeste. O diferencial de salário entre os empregados da agroindústria canavieira entre as regiões Norte-Nordeste e Centro-Sul do País foi verificado por Moraes (2004); Hoffmann (2007), Moraes (2007a) e Oliveira (2009), dentre outros.

A relação entre a educação e os rendimentos dos trabalhadores é amplamente abordada na literatura, e na maioria dos trabalhos observa-se a educação como determinante nos rendimentos dos trabalhadores. Dentre estes trabalhos, destacam-se Langoni (1973, apud Barros e Mendonça, 1995); Langoni (2005); Kassouf (1997); Hoffmann e Ney (2004); Hoffmann e Simão (2005).

No que se refere ao impacto dos sindicatos no mercado de trabalho, Arbache (2001), ao analisar os sindicatos e o mercado de trabalho no Brasil, encontra que as instituições são fundamentais para explicar o comportamento dos sindicatos e do desenvolvimento das barganhas coletivas. $\mathrm{O}$ autor afirma que a legislação sindical e as normas trabalhistas criam desincentivo para a barganha coletiva e ainda causam problemas para a coordenação macroeconômica.

No que se refere ao efeito dos sindicatos sobre a formação dos salários, o autor encontra que claramente os sindicatos contribuem para a formação dos salários, o que faz que os empregados sindicalizados ganhem um prêmio de salários em relação aos não sindicalizados com as mesmas características individuais. Apesar da legislação prever que os resultados da barganha coletiva sejam extensivos a todos os empregados da mesma categoria, incluindo os não sindicalizados (o que implicaria que o prêmio não deveria existir), o autor sugere que a existência do prêmio pode ser explicada, dentre outros fatores, pela não aplicação da lei. Segundo Arbache (2001), outra explicação é que os sindicatos estariam mais preocupados em negociar pisos salariais do que aumentos reais de salários. Quanto ao efeito dos sindicatos em reduzir a desigualdade de renda, que é um resultado usual na literatura internacional, o autor encontra resultado oposto para o caso do Brasil, ou seja, os sindicatos brasileiros estão associados com mais desigualdade salarial, e não com menos. As explicações para este fato encontram-se no referido trabalho.

Horn (2008) estuda a relação entre os resultados da barganha coletiva em dezessete unidades da indústria do Rio Grande do Sul, e a mudança no ambiente econômico entre 1979 e 1995 . O autor discute as teorias sobre os determinantes dos resultados das barganhas coletivas, de forma a permitir hipóteses sobre o caso específico da indústria manufatureira do Rio Grande do Sul. Os resultados estatísticos sugerem que a barganha coletiva tem sido sistematicamente influenciada pelo desemprego, pelos preços relativos da indústria, pela estabilização política iniciada em 1986. Especificamente no que se refere à negociação salarial o autor indica que esta tem sido influenciada pelo salário mínimo oficial.

Mischel e Walters (2003) mostram que os sindicatos têm um impacto impor- 
tante sobre os salários tanto dos empregados sindicalizados quanto dos não sindicalizados. Os autores concluem que os sindicatos elevam os salários dos empregados sindicalizados em aproximadamente $20 \%$, e ao incluir-se os benefícios, este percentual se eleva para $28 \%$. Os sindicatos fortes estabelecem um pagamento-padrão que os empregados não sindicalizados também seguem. Os autores concluem que a maior vantagem dos empregados sindicalizados em relação aos não sindicalizados refere-se aos benefícios, como seguro-saúde, planos de aposentadorias e férias.

Especificamente ao ambiente institucional e organizacional do mercado de trabalho da agroindústria canavieira, Moraes (2007a) verificou a existência de regras claras e específicas que regem o mercado de trabalho. A autora identificou haver, no estado de São Paulo, sindicatos de classe — patronais e de trabalhadores — fortes e atuantes, e negociações salariais conduzidas pelas referidas entidades no início de cada safra.

Cacciamali (2005) analisa o processo da reforma laboral ocorrida no Brasil a partir de meados da década de 1990, e os desafios enfrentados pelos sindicatos de trabalhadores. A autora faz uma importante análise sobre a formação e atuação dos sindicatos desde a era Vargas, salientando que na última década os mesmos têm seu poder de barganha diminuído por diversos fatores, dentre eles: (i) liberalização comercial (ii) existência de fatores que possibilitam maior substituição dos empregados (participação da mulher e dos jovens no mercado de trabalho; elevado desemprego; multifuncionalidade e polivalência na execução das atividades; aumento da subcontratação, que muitas vezes encobrem a relação de emprego; e flexibilização da legislação laboral). A autora ainda enumera as relações de emprego do setor informal, que da mesma forma enfraquece o poder de barganha dos sindicatos. O artigo finaliza expondo os múltiplos desafios do movimento sindical de forma a manter uma política de transformação da sociedade.

Para se analisar os determinantes dos rendimentos dos empregados da agroindústria canavieira são consideradas nesta pesquisa as variáveis identificadas na literatura citada, incluindo a filiação a sindicato de classe.

\section{METODOLOGIA E FONTE DE DADOS}

O modelo de equação de rendimentos estimado neste trabalho ${ }^{3}$ tem a seguinte especificação:

$$
y_{j}=\alpha+\sum \beta_{i} x_{i j}+u_{j}
$$

onde $\alpha_{i}$ e $\beta_{i}$ são parâmetros e $u_{j}$ são erros aleatórios heterocedásticos com as propriedades usuais. $\mathrm{O}$ índice $i$ distingue as diferentes variáveis explanatórias e o índice $j$ indica a observação (pessoa da amostra).

\footnotetext{
${ }^{3} \mathrm{O}$ modelo foi adaptado a partir do trabalho de Hoffmann e Simão (2005).
} 
A variável dependente $(y)$ é o logaritmo neperiano do rendimento mensal. $\mathrm{O}$ uso logaritmo do rendimento justifica-se pelo fato de que o rendimento tem distribuição aproximadamente log-normal.

Algumas das variáveis explanatórias utilizadas são binárias, que assumem o valor 1 quando o indivíduo pertence a determinado grupo e 0 quando não pertence. Lista-se a seguir as variáveis explanatórias incluídas nas equações estimadas.

1. Variável binária para sexo, que assume valor 1 para as mulheres e 0 para homens;

2. Variável binária para filiação à sindicato de classe, que assume valor 1 se filiado ao sindicato e 0 caso contrário;

3. Variável binária para a região produtiva, que assume valor 1 se pertence à região Norte-Nordeste e 0 se pertence à região Centro-Sul;

4. Idade da pessoa e também o quadrado desta idade, considerando-se que $y$ não varia linearmente com a idade. A idade é medida em dezenas de anos, para evitar que os coeficientes sejam muito pequenos. Se os parâmetros para a idade e idade ao quadrado forem $\beta_{1}$ e $\beta_{2}$, respectivamente, deve-se ter $\beta_{1}>0$ e $\beta_{2}<0$ e então o valor esperado de $y$ será máximo quando a idade for $-\frac{\beta_{1}}{2 \beta_{2}}$;

5. Escolaridade, variando de 0 (pessoa sem instrução ou menos de 1 ano de estudo) a 16, assumindo valor 18 para pessoas com mais de 17 anos de estudo.

Simão (2009) ressalta que grande parte dos trabalhos que analisam empiricamente a relação entre rendimentos e educação adota o modelo de Mincer (1974, apud Rezende e Willie, 2005), no qual o logaritmo dos rendimentos é uma função linear dos anos de educação. Contudo, estudos recentes têm mostrado que a taxa de retorno para cada ano adicional de estudo não é constante para todas as séries. ${ }^{4}$

Dois fatores podem explicar a variação na taxa de retorno à escolaridade, $o$ "efeito diploma", que refere-se ao fato de os salários aumentarem mais rapidamente com os anos extras de educação associados à concessão de certificados ${ }^{5}$ e o "threshold effect". Conforme Hoffmann e Simão (2005), chamando a escolaridade de $S$, nos modelos onde se considera-se a existência de um efeito-limiar (threshold effect), além da variável $S$ inclui-se a variável:

$$
S^{*}=Z(S-\lambda),
$$

onde $\lambda$ é o limiar, ou seja, é o valor da escolaridade a partir do qual a taxa de retorno da escolaridade torna-se maior, e $Z$ é uma variável binária que assume valor 0 para $S \leq \lambda$ e valor 1 para $S>\lambda$. Segundo os autores, indicando os coeficien-

\footnotetext{
${ }^{4}$ Crespo e Reis (2006), Hoffmann e Simão (2005).

${ }^{5}$ Conclusão de cada etapa no ensino formal, ou seja, últimos anos do Ensino Fundamental (8 ou 9 anos), do Ensino Médio (11 ou 12 anos) ou Superior (15 ou 16 anos), ou de pós-graduação.
} 
tes de $S$ e $S^{*}$ por $\beta_{3}$ e $\beta_{4}$, e chamando de $K$ a soma dos demais termos da equação de rendimentos, o valor esperado de $y$ é:

$$
E(y)=K+\beta_{3} S+\beta_{4} Z(S-\lambda)
$$

Quando $S \leq \lambda$, temos $Z=0$ e a expressão (1) se reduz a:

$$
E(y)=K+\beta_{3} S
$$

Quando $S>\lambda$, temos $Z=1$ e a expressão (1) torna-se:

$$
E(y)=K+\lambda \beta_{4}+\left(\beta_{3}+\beta_{4}\right) S
$$

Observa-se que quando $S=\lambda$, tanto a equação (1) quanto a (2) são iguais a $K+\beta_{3} \lambda$. Portanto, segundo Hoffmann e Simão (2005), em um sistema de eixos cartesianos ortogonais, com $E(y)$ no eixo das ordenadas e a escolaridade $S$ no eixo das abscissas, a expressão (1) representa uma linha poligonal com vértice no ponto de abscissas $S=\lambda$, sendo $\beta_{3}$ a inclinação do segmento que está antes do vértice e $\left(\beta_{3+} \beta_{4}\right)$ a inclinação do segmento que se inicia no vértice.

Os autores ressaltam que antes do limiar cada ano adicional de escolaridade está associado a um aumento de $\left[\exp \left(\beta_{3}\right)-1\right] 100 \%$ no rendimento das pessoas. Após o limiar, cada ano de escolaridade está associado a um aumento de $\left[\exp \left(\beta_{3}+\beta_{4}\right)-1\right] 100 \%$. Ou seja, o coeficiente $\beta_{3}$ é o efeito de cada ano adicional de escolaridade até o limiar l, e a partir deste ponto, esse efeito passa a ser $\left(\beta_{3}+\beta_{4}\right)$.

Hoffmann e Ney (2004), ao analisarem a desigualdade, escolaridade e rendimentos na agricultura, indústria e serviços, de 1992 a 2002, encontraram que o efeito da educação na renda se torna mais intenso a partir de 9 anos de estudo. Por sua vez, Hoffmann e Simão (2005), que analisaram os determinantes das pessoas ocupadas em Minas Gerais, em 2000; o limiar ocorreu aos 10 anos de estudo; Simão (2009), ao analisar os rendimentos das pessoas ocupadas para toda a economia, do estado de São Paulo, encontrou o efeito para 10 anos de estudo.

Neste trabalho, para se identificar a escolaridade a partir da qual a função educação altera sua declividade, ou seja, captar o "threshold effect", ou efeito limiar, foram estimadas várias regressões variando, em cada uma, o valor de $\lambda$, ou seja os anos de estudo. Dentre as equações estimadas, escolheram-se, para cada setor analisado, a de coeficiente de determinação $\left(R^{2}\right)$ mais alto.

Portanto, neste trabalho procura-se verificar a influência sobre os salários das seguintes variáveis: idade e escolaridade (que captam o efeito do treinamento e da experiência das pessoas), segmentações de mercado (sexo), as diferenças regionais e a influência do ambiente organizacional (presença ou ausência de sindicatos de classe). O modelo pode ser representado pela seguinte equação:

$$
Y=\beta_{1} I d+\beta_{2} I d^{2}+\beta_{3} E s c+\beta_{4} Z_{1 i}(E s c-\lambda)+\beta_{5} \text { In hort }+\theta_{1} Z_{2 i}+\theta_{2} Z_{3 i}+\theta_{3} Z_{4 i} \text { Onde: }
$$


$I d=$ Idade e $I d^{2}$ é a idade ao quadrado;

$E s c=$ escolaridade

$Z_{1 i}=$ Variável binária que assume o valor 0 para escolaridade $\leq \lambda$ e valor 1 para escolaridade $>\lambda$. O valor de $\lambda$ foi considerado 10 anos de estudo para o setor de cana-de-açúcar e de 11 anos de estudo para a indústria do açúcar e do álcool. ${ }^{6}$

hort $=$ horas semanais trabalhadas

$Z_{2 i}=$ Variável Binária que assume o valor 1 se o indivíduo $i$ é filiado ao Sindicato valor 0 se não é filiado

$Z_{3 i}=$ Variável binária que assume o valor 1 se o indivíduo $i$ pertence à região Norte-Nordeste valor 0 se pertence à região Centro-Sul

$Z_{4 i}=$ Variável binária que assume o valor 1 se o indivíduo $i$ for mulher e valor 0 se for homem

De acordo com a literatura (Eisemberg, 1997; Prado, 1990) existem determinantes históricos que podem explicar as diferenças regionais. O efeito destas variáveis provavelmente estará confundido com o efeito da variável regional $\left(Z_{3}\right)$.

O programa utilizado foi o software Statistical Analysis System (SAS), versão 9.1.3.

\section{FONTE DE DADOS}

Os dados secundários são os microdados da Pesquisa Nacional por Amostra de Domicílios (PNAD), do Instituto Brasileiro de Geografia e Estatística - IBGE, e referem-se aos empregados dos setores de produção de cana-de-açúcar, açúcar e álcool. ${ }^{7}$ Para análise da evolução de alguns indicadores, são usadas as PNADs de diversos anos. Especificamente às regressões estimadas, foram usados os dados dos empregados dos anos de 1993 e 2006.

A fim de verificar se houve mudanças ao longo do tempo dos impactos das variáveis analisadas sobre os rendimentos dos empregados, são estimadas duas equações, uma para o ano de 1993 e outra para o ano de 2006, que são anos sem eventos importantes na economia brasileira que pudessem ter influência sobre os dados e viesar os resultados. Antes de 2003 não é possível separar nos dados da PNAD as usinas de açúcar e destilarias de álcool, porque estão agregados à nível

\footnotetext{
${ }^{6}$ Conforme indicado pela literatura, escolheu-se a regressão com o coeficiente de determinação $R^{2}$ mais alto. Para a cana-de-açúcar, ano de 1993, os valores encontrados para os coeficientes de determinação conforme variaram-se os anos de estudo do efeito limiar foram: para 9 anos, $R^{2}=0,364175$; para 10 anos, $R^{2}=0,364411$; para 11 anos, $R^{2}=0,363407$. Para o ano de 2006, os valores dos coeficientes de determinação encontrados nas regressões foram: para 9 anos, $R^{2}=0,403398$; para 10 anos, $R^{2}=$ 0,403795; para 11 anos, $R^{2}=0,402310$. Para a indústria do açúcar e do álcool, os valores encontrados para os coeficientes de determinação $\mathrm{R}^{2}$ foram: para 9 anos, $\mathrm{R}^{2}=0,584780$; para 10 anos, $\mathrm{R}^{2}=$ 0,597327; para 11 anos, $\mathrm{R}^{2}=0,597206$.

${ }^{7}$ Os códigos da variável atividade (V9907) utilizados foram: cana-de-açúcar: 1105; fabricação e refino de açúcar: 15041; álcool: 23400.
} 
de indústria de alimentos e de combustíveis. Dessa forma, para o ano de 1993 será estimada somente a equação para o setor de cana-de-açúcar, e portanto a comparação possível de ser feita é para este setor.

Foram coletadas informações primárias referentes ao funcionamento do mercado de trabalho da agroindústria canavieira. Em março de 2008 foi realizada uma viagem a Pernambuco (Recife) e Alagoas (Maceió) na qual foram realizadas entrevistas com os representantes dos sindicatos de trabalhadores e patronais dos referidos estados, de modo a compreender o mecanismo das negociações salariais nestes estados. A identificação das principais entidades representativas das categorias profissional e patronal, bem como dos respectivos presidentes dos sindicatos, responsáveis pelas negociações, foi feita através de consulta a pesquisadores do tema das referidas regiões.

Também foram realizadas visitas à duas usinas de açúcar e álcool, uma no estado de Alagoas e outra de Pernambuco, bem como feitas reuniões com pesquisadores daqueles estados, especialistas da agroindústria canavieira, amplamente reconhecidos pelas pesquisas e publicações sobre o tema.

\section{RESULTADOS}

\section{O ambiente organizacional: os sindicatos de classe}

O Sindicalismo brasileiro é organizado em três níveis: municipal, estadual e nacional. Nos municípios, temos que a representação da categoria é feita nos Sindicatos (um mesmo Sindicato pode englobar vários municípios vizinhos). Os Sindicatos normalmente são filiados à entidade estadual, denominada Federação. Por sua vez, as várias Federações costumam ser filiadas à Confederação nacional.

A organização sindical dos setores de cana-de-açúcar, indústrias do açúcar e do álcool dos estados de São Paulo, Pernambuco e Alagoas diferem entre si em alguns aspectos.

No estado de São Paulo, no plano estadual, existem três entidades representativas dos donos das usinas, destilarias e dos fornecedores de cana independentes, e três entidades representativas dos trabalhadores, ${ }^{8}$ que negociam reajustes salariais e demais condições de forma separada.

No estado de Pernambuco a organização sindical difere do estado de São Paulo, com menos entidades representando as diferentes categorias. ${ }^{9}$ Naquele es-

\footnotetext{
${ }^{8}$ Os empregados da indústria do álcool são representados pela Federação dos Trabalhadores nas Indústrias Químicas e Farmacêuticas do Estado de São Paulo (FEQUIMFAR), e pelos sindicatos filiados. Por sua vez, na indústria do açúcar, os empregados são representados pela Federação dos Trabalhadores nas Indústrias de Alimentação do Estado de São Paulo (FETIASP) e sindicatos filiados.

${ }^{9}$ Os empregados são representados pelo Sindicato dos Trabalhadores nas Indústrias do Açúcar e do Álcool do Estado de Pernambuco, e pelo lado da indústria responde o Sindicato da Indústria do Açúcar e do Álcool no Estado de Pernambuco (SINDAÇUCAR/PE). Por sua vez os empregados da lavoura
} 
tado as convenções coletivas de trabalho para os empregados da indústria do açúcar e do álcool são negociadas pelas mesmas entidades, e a mesma convenção se aplica aos empregados dos dois setores.

O movimento sindical tem importante tradição no estado de Pernambuco, sendo que a Federação dos Trabalhadores na Agricultura do estado de Pernambuco (FETAPE) foi fundada em 6 de junho de 1962. Segundo informações da FETAPE, na época da pesquisa a mesma era constituída por 178 Sindicatos de Trabalhadores Rurais, distribuídos nas seguintes regiões do estado: 73 Sindicatos na região do Agreste, atingindo 343.260 trabalhadores rurais sindicalizados; 53 Sindicatos na região do Sertão, atingindo 183.569 sindicalizados; 50 na região da Mata, atingindo 174.766 sindicalizados. Desde 1979 a FETAPE tem atuado nas campanhas salariais dos empregados da lavoura da cana-de-açúcar, representando ao redor de 250 mil canavieiros nas campanhas salariais, e em outras questões relativas às condições de trabalho.

Conforme Rufino ${ }^{10}$ (2008), a FETAPE tem tido importante atuação, realizando campanha salarial unificada para os estados de Pernambuco, Sergipe, Alagoas, Paraíba e Rio Grande do Norte. Contudo, o entrevistado reconhece que dado o alto desemprego da região Nordeste e os altos níveis de pobreza da região, muitos empregados aceitam trabalhar informalmente, em condições piores do que as negociadas nos acordos coletivos. Nos anos recentes o entrevistado acredita que a situação da informalidade, bem como o uso do trabalho infantil, tenham melhorado bastante, principalmente pela atuação mais rigorosa dos Ministérios Público e do Trabalho.

Neste sentido, Guerra ${ }^{11}$ (2008) salienta a assinatura do Pacto Paulo Freire, de Erradicação do Trabalho Infantil e pela Profissionalização do Adolescente no Setor Sucroalcooleiro do estado de Pernambuco, assinado em 1997, que segundo o entrevistado em muito contribuiu para a eliminação do trabalho infantil na agroindústria canavieira de Pernambuco. Os resultados de Moraes (2007b) corroboram a redução do uso de trabalho infantil no setor.

Por sua vez, a organização sindical patronal no estado de Alagoas assemelha-se à de Pernambuco, com as mesmas entidades patronais deste estado representando tanto a indústria do açúcar quanto a do álcool. ${ }^{12}$

\footnotetext{
canavieira nesse estado são representados pela Federação dos Trabalhadores na Agricultura do Estado de Pernambuco e do lado patronal tem-se o Sindicato da Indústria do Açúcar no Estado de Pernambuco (SINDAÇUCAR/PE) e o Sindicato dos Cultivadores de Cana-de-Açúcar no Estado de Pernambuco.

${ }^{10}$ Entrevista pessoal com Expedito Rufino de Araújo, diretor do Projeto Dom Helder Câmara, realizada no Recife, em março de 2008, na sede da FETAPE.

${ }^{11}$ Entrevista pessoal com Marcelo Cavalcanti Guerra, superintendente do Sindaçucar/PE, realizada no Recife, em março de 2008.

${ }^{12}$ Sindicato da Indústria do Açúcar e do Álcool no Estado de Alagoas (SINDAÇUCAR/AL) e Federação da Indústria do Estado de Alagoas. Os empregados por sua vez são representados por entidades diferentes: Sindicato Interestadual dos Trabalhadores nas Indústrias da Fabricação de Álcool nos Esta-
} 
Algumas pessoas entrevistadas durante a pesquisa de campo consideram que a Federação dos Trabalhadores Agrícolas de Alagoas - FETAGAL precisaria melhorar sua atuação. Segundo Carvalho ${ }^{13}$ (2008), embora a FETAPE/PE e FETAGAL negociem a mesma pauta nas discussões com os respectivos sindicatos patronais, a Federação alagoana tem menos força, tanto por ter poucos afiliados, como pela sua própria criação, conforme exposto a seguir.

O entrevistado salienta que existe um excesso de oferta de mão-de-obra na época da safra (setembro a março), formada principalmente pelos migrantes do sertão alagoano, que vem em direção às zonas canavieiras em busca de emprego devido à seca e falta de trabalho no verão nas suas regiões de origem. O grande contingente de migrantes na região de Maceió faz reduzir os salários e contribui para a manutenção da informalidade existente. Os migrantes do sertão não se filiam aos sindicatos das regiões canavieiras, o que enfraquece as bases locais. $\mathrm{O}$ entrevistado relata que os sindicatos profissionais da indústria também não têm a mesma representatividade que os de outros estados.

Carvalho cita ainda, na comparação com São Paulo, as diferentes origens das relações trabalhistas no setor canavieiro. Enquanto nesse estado a origem da lavoura canavieira deu-se no sistema de colonato, com os imigrantes italianos, nos estados de Pernambuco e Alagoas as relações sociais originaram-se no regime escravocrata, o que as tornam diferentes, e faz as mudanças nas relações de trabalho nesses estados mais lentas. Contudo, o entrevistado salienta que nos anos recentes uma geração mais jovem de empresários deste setor está contribuindo para melhorias das condições de trabalho.

Durante a realização desta pesquisa foi realizada uma entrevista com o então presidente da FETAGAL. Da mesma forma que o relato de alguns entrevistados, observou-se um quadro técnico menos preparado para as negociações que os dos demais sindicatos. Segundo o entrevistado, os problemas de informalidade do setor reduziram-se muito ao longo do tempo, e que em sua maioria encontram-se nas lavouras de fornecedores de cana, sendo que nas usinas os principais problemas já haviam sido sanados. Ao ser questionado sobre a atuação da Federação para a resolução das pendências usualmente relatadas nas lavouras canavieiras, tais como: alojamentos inadequados, falta de uso de equipamentos de proteção, transporte, descumprimento de itens previstos na norma NR31, dentre outros problemas, o entrevistado alegou que a maior parte dos problemas está solucionada, e que houve melhoria significativa nos anos recentes.

dos de Alagoas e Sergipe, e pelo Sindicato dos Trabalhadores na Indústria do Açúcar do Estado de Alagoas. As convenções coletivas de trabalho são específicas para cada setor. Na área agrícola, os empregados da lavoura da cana-de-açúcar são representados pela Federação dos Trabalhadores Agrícolas de Alagoas - FETAGAL e Sindicatos dos Empregados Rurais associados. Pelo lado patronal, são responsáveis a Federação da Agricultura do Estado de Alagoas — FAEAL e a Associação dos Plantadores de Cana de Alagoas - ASPLANA e o Sindicato da Indústria do Açúcar no Estado de Alagoas.

${ }^{13}$ Cícero Péricles de Carvalho, professor da Universidade Federal de Alagoas e pesquisador do Setor Sucroalcooleiro. Entrevista pessoal, março de 2008. 
Contudo, em março de 2008, os auditores fiscais do Grupo Móvel do Ministério do Trabalho e Emprego, que estava em operação no estado de Alagoas, fiscalizando as condições de trabalho nas usinas da região, interditou algumas usinas do estado, dadas as várias irregularidades encontradas.

Os indicadores socioeconômicos do estado de Alagoas para a cultura da cana-de-açúcar, especificamente no que se refere à informalidade, são os piores de todos os estados estudados, o que deve ser analisado considerado-se as condições específica deste estado. Carvalho (2007) traz alguns dados do estado que ilustram o problema na pobreza na região: (i) em 2006, Alagoas apresentou as maiores taxas de analfabetismo e mortalidade infantil e a menor expectativa de vida do País; (ii) foi o penúltimo estado colocado no ranking de Índice de Desenvolvimento Humano (IDH) em 2003. O autor salienta a importância do Programa Federal Bolsa Família em Alagoas, que em 2006 destinava 22 milhões de reais mensalmente a 342 mil famílias alagoanas, injetando no mercado de bens de consumo popular 260 milhões de reais por ano. Segundo estimativas do autor, ao comparar os recursos do Bolsa Família destinados à Alagoas com a massa salarial gerada pelo corte de cana, tem-se que esta última representa um terço das transferências realizadas pelo Bolsa Família para Alagoas.

\section{Evolução do número de empregados, nível salarial, educação e idade dos empregados}

Segundo os dados extraídos da PNAD, no ano de 2006 havia 532.263 empregados $^{14}$ no setor de cana-de-açúcar. Ao considerar-se todas as pessoas ocupadas, este total é de 608.305 pessoas, mas optou-se pela análise dos dados referentes aos empregados, visto que o foco é o entendimento das variáveis que impactam os salários. Também entende-se que são os empregados que estão sujeitos às negociações salariais realizadas pelos sindicatos de classe.

Os empregados da lavoura canavieira estavam divididos entre as duas regiões produtoras de forma quase equivalente ( $49 \%$ na região Centro-Sul e os demais $51 \%$ na região Norte-Nordeste). São Paulo, apesar de ser o maior estado produtor, com aproximadamente $60 \%$ da produção, respondia por $29,4 \%$ dos empregos (aproximadamente 170 mil), devido à maior mecanização das atividades de colheita e de plantio da cana-de-açúcar.

Não há grande variação da idade média dos trabalhadores entre as regiões produtoras, sendo que esta variou entre 33,4 e 36,3 anos. Quanto ao sexo dos empregados, observou-se que embora haja predominância nas diversas regiões de homens (a proporção de mulheres era de aproximadamente 8\%), no estado de São Paulo a participação de mulheres era maior $(11,9 \%)$ em comparação com as outras

\footnotetext{
${ }^{14}$ Exclui-se da amostra as pessoas que trabalhavam por conta própria, empregadores, produtores para consumo próprio e os não remunerados.
} 
regiões produtoras. A escolaridade média era baixa de forma geral ( 4 anos de estudo), sendo ainda pior na região Norte-Nordeste (3 anos).

Ao se analisar a proporção entre os empregados formais e informais para o ano de 2006, observou-se que a participação dos empregados contratados formalmente (com registro em carteira) era relativamente alta $(74,2 \%)$, principalmente ao se comparar com a elevada informalidade da agricultura brasileira. Também pôde ser verificado que a formalização tem aumentado ao longo do tempo. Segundo Moraes (2007b), em 1992 a proporção dos empregados formais na cultura da cana-de-açúcar era de 53,6\%. Esta tendência foi verificada para ambas as regiões produtoras: a região Norte-Nordeste em 1992 tinha 42,3\% de empregados formais, em 2006 aumentou para $65 \%$; na região Centro-Sul a proporção foi de $66 \%$ em 1992 para 83,2\% em 2006. O estado de São Paulo, o maior produtor de cana-de-açúcar do Brasil, apresentou os melhores indicadores: a formalização passou de 80,4\% em 1992 para 91,8\% em 2006.

A Tabela 1 apresenta informações sobre o tipo de vínculo do emprego (permanente ou temporário), o salário médio e proporção dos empregados filiados aos sindicatos, para o Brasil no agregado, para as diferentes regiões produtoras e para o estado de São Paulo.

Observa-se que a proporção dos empregados temporários em 2006 era menor que dos permanentes, sendo que em São Paulo o emprego temporário representava $34 \%$ do total. Com o avanço da colheita mecanizada no estado de São Paulo (e também em alguns estados da região Centro-Sul), espera-se que a proporção dos temporários se reduza ainda mais: os investimentos em treinamento e qualificação feito pelas empresas para que os trabalhadores se tornem aptos a operar uma colhedora de cana provavelmente farão com que as mesmas decidam aumentar os contratos de trabalho de tempo indeterminado, para evitar que o empregado qualificado trabalhe em outra empresa na safra seguinte.

Tabela 1: Cana-de-Açúcar - formalização, emprego temporário, salários e filiação sindical

\begin{tabular}{l|c|c|c}
\hline & $\begin{array}{c}\text { Empregados } \\
\text { Temporários (\%) }\end{array}$ & $\begin{array}{c}\text { Salário } \\
\text { Médio* (R\$) }\end{array}$ & $\begin{array}{c}\text { Filiação } \\
\text { Sindicato (\%) }\end{array}$ \\
\hline Brasil & 44,6 & 473,30 & 36,7 \\
\hline Norte-Nordeste & 47,9 & 346,92 & 40,7 \\
\hline Centro-Sul & 41,4 & 597,01 & 32,7 \\
\hline São Paulo & 34 & 659,50 & 36,3 \\
\hline
\end{tabular}

Fonte: elaborado a partir de PNAD (2006)

* Salários em reais de setembro de 2006

Quanto aos salários médios, observa-se que variaram entre as regiões, sendo aproximadamente $72 \%$ mais alto na região Centro-Sul em relação à Norte-Nor- 
deste. No que se refere à sindicalização dos empregados da cultura da cana-de-açúcar, encontrou-se que o número de empregados sindicalizados em 2006 era de aproximadamente 195 mil, representando $36,7 \%$ do total dos empregados. Interessante observar que pelos dados a PNAD a proporção dos empregados que se declararam ser sindicalizados era maior na região Norte-Nordeste do que na Centro-Sul.

Segue-se análise similar para as indústrias do açúcar e do álcool. Ressalta-se a dificuldade de se separar com exatidão os empregados de cada setor, visto que grande parte das empresas em 2006 produziam ambos os produtos, açúcar e álcool. A classificação entre pertencer a um ou outro grupo nestes casos é o que o empregado respondeu ao ser entrevistado (provavelmente o setor que ele considera ser o mais importante).

Do total dos empregados da indústria do açúcar (161.620) verificou-se que $66,7 \%$ eram da região Centro-Sul, sendo o estado de São Paulo responsável por aproximadamente $50 \%$ dos empregos. Na indústria do álcool, em 2006 foram empregadas 71.083 pessoas, sendo que a proporção dos empregados da região Centro-Sul era ainda maior $(92,3 \%)$.

Quanto ao sexo dos empregados, encontrou-se tendência similar à observada anteriormente, de maioria de empregados masculinos: na indústria do açúcar a participação dos homens atingiu aproximadamente $95 \%$ e na indústria do álcool foi de 92,6\%, considerando-se o agregado do Brasil.

Quanto à idade média dos empregados (que variou entre 34,7 a 36,8 anos), observou-se que não há grande diferença nem entre as regiões nem entre as indústrias. Também não há diferenças importantes quando comparada à idade média dos empregados da cultura da cana-de-açúcar.

A Tabela 2 traz os dados referentes à formalização do emprego, filiação aos sindicatos, escolaridade e salários médios para as indústrias do açúcar e do álcool. Nota-se que a participação dos empregados formais (com registro em carteira) é alta em ambos os setores, em todas as regiões, sendo que no estado de São Paulo a totalidade dos empregados declarou ter carteira de trabalho assinada.

No que se refere à sindicalização, ao se considerar o Brasil no agregado, verifica-se proporção maior de empregados sindicalizados na indústria do açúcar $(48,4 \%)$ do que na indústria do álcool $(40,8 \%)$. Ambas participações são maiores que a dos empregados sindicalizados da cultura da cana-de-açúcar $(35,1 \%)$. Ressalta-se a pequena participação dos empregados sindicalizados da indústria do álcool da região Norte-Nordeste (17,3\%), que se destoa das demais. 
Tabela 2: Indicadores socioeconômicos dos empregados

das indústrias do açúcar e do álcool — 2006

Indústria do Açúcar

\begin{tabular}{lcccc}
\hline & $\begin{array}{c}\text { Participação } \\
\text { Empregados } \\
\text { com carteira } \\
(\%)\end{array}$ & $\begin{array}{c}\text { Participação } \\
\text { Filiação } \\
\text { Sindicato } \\
(\%)\end{array}$ & $\begin{array}{c}\text { Escolaridade } \\
\text { Média }\end{array}$ & $\begin{array}{c}\text { Salário } \\
\text { Médio* }\end{array}$ \\
\hline Brasil & 97,7 & 48,4 & 7,9 & (R\$) \\
Norte-Nordeste & 94,3 & 50,6 & 6,6 & 1143,22 \\
Centro-Sul & 99,5 & 47,2 & 8,6 & 834,25 \\
São Paulo & 100,0 & 47,8 & 8,9 & 1297,30 \\
\hline & & & & 1467,87 \\
\hline & Emprego com & Filiação & Escolaridade & Salário \\
& carteira (\%) & Sindicato (\%) & Média & Médio* \\
(anos estudo) & (R\$) \\
\hline Brasil & $96,9 \%$ & $40,8 \%$ & 8,6 & 1204,90 \\
Norte-Nordeste & $82,5 \%$ & $17,3 \%$ & 6,8 & 505,13 \\
Centro-Sul & $98,1 \%$ & $42,7 \%$ & 8,8 & 1263,24 \\
São Paulo & $100,0 \%$ & $48,9 \%$ & 9,2 & 1518,08 \\
\hline
\end{tabular}

Fonte: elaborado a partir dos dados da PNAD (2006)

* salários em reais de setembro de 2006

A principal diferença entre os indicadores dos empregados da indústria do açúcar e do álcool com os da lavoura canavieira está na escolaridade média. A escolaridade média da indústria do álcool é sempre mais elevada que da indústria do açúcar, mas as diferenças são relativamente pequenas. Contudo, ao se analisar a diferença destes empregados com os da área agrícola, nota-se que para o Brasil, a escolaridade média da indústria do açúcar é 113,5\% mais alta que a dos empregados da lavoura canavieira, e ao se comparar a escolaridade média da indústria do álcool com a da área agrícola este percentual é ainda maior (132,43\%). Este é um dos fatores que pode explicar as diferenças nos rendimentos auferidos pelos empregados da indústria e da área agrícola.

Para se verificar se algumas características do emprego variavam entre os grupos de empregados sindicalizados e de não sindicalizados da cultura da cana-de-açúcar, apresentam-se na Tabela 3 os dados de formalização e tipo de vínculo do emprego - temporário e permanente - para os dois grupos. Observa-se que dos empregados sindicalizados, 93,7\% tinham carteira de trabalho, percentual mais elevado quando se compara com os não sindicalizados, dos quais $62,9 \%$ tinham carteira de trabalho. A proporção dos empregados temporários entre os sindicalizados era menor $(35,1 \%)$ do que os não sindicalizados $(51,4 \%)$. Ambas informações sinalizam melhor qualidade de emprego para os empregados sindicalizados. 
Tabela 3: Cana-de-Açúcar: indicadores

de formalização e de sindicalização. Brasil, 2006

\begin{tabular}{lccc}
\hline & $\begin{array}{c}\text { Número } \\
\text { Empregados }\end{array}$ & $\begin{array}{c}\text { Emprego com } \\
\text { carteira (\%) }\end{array}$ & $\begin{array}{c}\text { Emprego } \\
\text { Temporário (\%) }\end{array}$ \\
\hline Empregados Sindicalizado & 195.255 & $93,7 \%$ & $35,1 \%$ \\
Empregados não Sindicalizado & 337.008 & $62,9 \%$ & $51,4 \%$ \\
\hline
\end{tabular}

Fonte: Elaborado a partir dos dados da PNAD (2006)

Já para os setores industriais, observou-se não haver diferenças acentuadas entre ser ou não sindicalizado sobre o percentual de empregados formais, visto que em ambas categorias, dos dois setores, o nível de formalização é alto.

Ao se comparar a renda média dos empregados sindicalizados com os não sindicalizados, para os empregados dos três setores, cana-de-açúcar, açúcar e álcool, observa-se que a renda média dos primeiros em 2006 era sempre mais alta, conforme indicado na Tabela 4.

Tabela 4: Renda média* dos empregados sindicalizados e não sindicalizados. Brasil, 2006

\begin{tabular}{l|c|c|c}
\hline & Cana-de-Açúcar & Álcool & Açúcar \\
\hline Todos empregados & $\mathrm{R} \$ 473,30$ & $\mathrm{R} \$ 1.204,90$ & $\mathrm{R} \$ 1.143,22$ \\
\hline Empregados sindicalizados & $\mathrm{R} \$ 520,94$ & $\mathrm{R} \$ 1.596,69$ & $\mathrm{R} \$ 1.383,20$ \\
\hline Empregados não sindicalizados & $\mathrm{R} \$ 445,70$ & $\mathrm{R} \$ 935,08$ & $\mathrm{R} \$ 918,43$ \\
\hline
\end{tabular}

Fonte: elaborado a partir dos dados da PNAD

* Em reais de setembro de 2006

Para a lavoura da cana-de-açúcar, a renda média dos empregados sindicalizados era $16,7 \%$ maior que a dos não sindicalizados; para os empregados da indústria do álcool esta diferença era mais acentuada, de $70,7 \%$, e para a indústria do açúcar a renda média dos empregados sindicalizados era 50,6\% maior, o que indica efeito positivo da sindicalização sobre a renda média.

Outra análise para se verificar a influência do fato de ser ou não sindicalizado sobre as condições de trabalho é a proporção dos empregados de ambas as categorias por faixa de renda. Considerando-se a proporção de empregados sindicalizados e não sindicalizados em seis faixas de renda (até meio salário mínimo; maior que meio a um salário mínimo; maior que um a dois salários mínimos; maior que dois a três salários mínimos; maior que três a três e meio salários mínimos, e maior que 3,5 salários mínimos) observou-se que as maiores diferenças entre as duas categorias estavam nas seguintes faixas salariais: (i) menor que meio salário mínimo, na qual 2,0\% dos sindicalizados estavam nesta categoria, enquanto para os não sindicalizados esta proporção era maior (10,5\%); (ii) na faixa maior que 2 a 3 salários mínimos, na qual 14,3\% dos sindicalizados estavam nesta categoria e 6,3\% dos sindicalizados. Para as demais, não observou-se influência positiva para os sindi- 
calizados (a proporção dos sindicalizados nas faixas de rendas mais altas era ligeiramente superior em relação aos não sindicalizados).

\section{Regressões estimadas}

Foram estimadas equações de rendimentos para os empregados da cultura da cana-de-açúcar, e para a indústria do açúcar e do álcool de forma agregada. Conforme salientado anteriormente, considerando-se que até 2006 a grande maioria das usinas fabricavam tanto açúcar quanto álcool, a maior parte dos empregados que se declararam de um ou de outro setor provavelmente trabalhavam em usinas de açúcar com destilarias anexas, e não trabalhavam exclusivamente em um ou no outro setor, optou-se por estimar a equação de rendimentos considerando-se os empregados dos dois setores de forma agregada. ${ }^{15}$

No Apêndice 1 encontram-se os resultados das duas equações de rendimento estimadas para os empregados do setor de cana-de-açúcar, para os anos de $1993 \mathrm{e}$ 2006, e no Apêndice 2 apresenta-se a equação estimada para os empregados dos setores de açúcar e de álcool de forma agregada para 2006. O ajustamento das equações foi feito pelo método dos mínimos quadrados ponderados, usando o peso ou fator de expansão, fornecido pelo IBGE, associado a cada pessoa da amostra. Para o ano de 1993, a amostra era composta por 1062 pessoas, e para 2006, por 962 pessoas.

Em ambas as equações estimadas para os empregados da cultura da cana-de-açúcar as variáveis utilizadas foram as mesmas, e todos os coeficientes foram estatisticamente significativos a $1 \% .{ }^{16} \mathrm{O}$ efeito da educação foi captado através da relação entre o logaritmo do rendimento $(y)$ e a escolaridade $(S)$ em forma de poligonal, cujo vértice tem abscissa igual a 10, que permitem estimar os retornos específicos a cada ano de estudo adicional. Foi possível perceber que para a lavoura de açúcar, para os anos de 1993 e 2006, o efeito limiar se dá aos 10 anos de estudo. ${ }^{17} \mathrm{~A}$ análise dos resultados indica que a taxa de retorno à escolaridade aumenta

\footnotetext{
${ }^{15}$ Em 2007 existiam na região Centro-Sul existiam 298 unidades industriais, sendo 192 empresas mistas, 100 destilarias de álcool, 6 usinas de açúcar; na região Norte-Nordeste havia 49 empresas mistas, 20 destilarias de álcool e 9 usinas de açúcar.

${ }^{16}$ Ressalta-se que ao se estimar as equações com os dados disponíveis na PNAD as estimativas dos coeficientes são viesadas, pois não se trabalha com todas as variáveis que explicam os rendimentos dos empregados.Várias características pessoais que afetam os rendimentos não são disponíveis na PNAD e podem estar correlacionadas com algumas variáveis utilizadas: por exemplo, a ambição da pessoa, que pode estar associada com escolaridade, o fato do empregado ser mais "brigão" estar relacionado com pertencer ou não ao sindicato.

${ }^{17}$ Conforme ressaltado anteriormente (nota de rodapé 6), para a determinação do limiar foi escolhido a equação de maior coeficiente de determinação. Para a cana-de-açúcar, ano de 1993, os valores encontrados para os coeficientes de determinação conforme variaram-se os anos de estudo do efeito limiar foram: para 9 anos, $R^{2}=0,364175$; para 10 anos, $R^{2}=0,364411$; para 11 anos, $R^{2}=0,363407$. Para o ano de 2006, os valores dos coeficientes de determinação encontrados nas regressões foram: para 9 anos, $R^{2}=0,403398$; para 10 anos, $R^{2}=0,403795$; para 11 anos, $R^{2}=0,402310$.
} 
consideravelmente a partir de 10 anos de estudo. Em 1993, até 10 anos de estudos, cada ano adicional de estudo implicava um acréscimo de 6,35\% no rendimento estimado. A partir do limiar de 10 anos, esse aumento passava a 29,03\%. Da mesma forma, para o ano de 2006 observa-se a mudança na taxa de retorno à escolaridade a partir de 10 anos: até 10 anos, cada ano adicional de estudo implicava um acréscimo de $2,36 \%$ no rendimento estimado, e a partir do limiar de 10 anos, esse aumento passa a ser de $12,27 \%$.

A elasticidade do rendimento mensal em relação ao tempo semanal de trabalho em 1993 foi estimada em 0,7943; e para o ano de 2006 em 0,6768, ambas menores que 1 , indicando que o prolongamento do tempo de trabalho é feito com prejuízo da produtividade.

Os coeficientes das binárias relativas à sexo indicam que tanto no ano de 1993 como no ano de 2006 as mulheres tendiam a ganhar menos que os homens. Descontados os efeitos das demais variáveis incluídas no modelo, em 1993 uma mulher tendia a ganhar $24,93 \%$ menos, e em 2006, esta redução era de 20,74\%. Além da discriminação salarial contra as mulheres usualmente encontrada na literatura, ressalta-se que parcela importante da amostra é de cortadores de cana-de-açúcar, cujo pagamento é feito por produtividade, que pode ser menor para as mulheres devido à menor força física.

O coeficiente da binária que capta o efeito regional indica que os empregados da região Norte-Nordeste tendiam a ganhar menos que os empregados da região Centro-Sul. Descontados os efeitos das demais variáveis, em 1993 o rendimento médio mensal era 43,90\% menor na região Norte-Nordeste. A diferença dos rendimentos entre os empregados das duas regiões reduziu-se ao longo do tempo, mas em 2006 os empregados da região Norte-Nordeste ganhavam 34,81\% menos que os da região Centro-Sul.

Quanto ao efeito do empregado ser sindicalizado sobre o rendimento médio mensal, encontrou-se que os empregados da lavoura canavieira sindicalizados tendiam a ganhar $14,26 \%$ a mais em 1993 e $22,46 \%$ a mais em 2006 , em relação aos não sindicalizados, o que corrobora a hipótese de que os sindicatos têm se mostrado atuantes nas negociações salariais, principalmente nos anos recentes.

Portanto, observou-se que para as equações de rendimento estimadas para os empregados da cultura da cana-de-açúcar, para os dois anos analisados, 1993 e 2006, as variáveis significativas foram as mesmas, variando apenas na magnitude dos respectivos coeficientes.

Para a equação de rendimento estimada para os empregados da indústria do açúcar e do álcool considerada como uma indústria agregada (Apêndice 2) encontrou-se que os coeficientes das seguintes variáveis foram estatisticamente significativos, embora a diferentes níveis de significância: sexo, idade, escolaridade, efeito limiar da escolaridade, filiação à sindicato e região. Os coeficientes das variáveis idade ao quadrado e logaritmo das horas trabalhadas não foram estatisticamente significativos.

Os resultados indicam que as mulheres tendiam a ganhar 30,15\% menos que os homens. Quanto ao efeito da escolaridade sobre os salários, o efeito limiar para 
anos de estudo também foi captado para 10 anos de estudo. ${ }^{18}$ Os dados mostram que cada ano adicional de estudo, até 10 anos de estudo, tinha um impacto na renda média mensal de $3,78 \%$, e após 10 anos de estudo o acréscimo na renda de cada ano adicional de estudo era de $24,43 \%$.

O efeito regional também influenciava o rendimento em 2006: os empregados da região Norte-Nordeste tendiam a ganhar $30,15 \%$ menos que os do Centro-Sul em 2006.

Quanto ao coeficiente da variável binária sindicato, encontrou-se que o mesmo é significativo a $10 \%$, sendo que os empregados sindicalizados tendiam a ganhar $8,03 \%$ a mais que os não sindicalizados.

Conforme salientado anteriormente, Moraes (2004) aponta a forte atuação dos sindicatos de trabalhadores nas discussões salariais dos setores analisados no estado de São Paulo. Na pesquisa de campo realizada neste trabalho verificou-se que no estado de Pernambuco a representação sindical dos trabalhadores (FETAPE) tem tido importante participação nas negociações coletivas de trabalho, realizando campanha salarial unificada para os estados de Pernambuco, Sergipe, Alagoas, Paraíba e Rio Grande do Norte. Contudo, os altos níveis de pobreza e de desemprego da região Nordeste fazem com que muitos empregados aceitam trabalhar informalmente e portanto não sindicalizados, em condições piores do que as negociadas nos acordos coletivos.

Mesmo considerando que em Alagoas atuação sindical, conforme a pesquisa de campo, é menos eficiente que a dos demais estados analisados, esperava-se que dada a existência e atuação dos sindicatos de classe nos principais estados produtores, a influência da filiação ao sindicato de classe sobre os rendimentos fosse captada nos modelos estimados, o que de fato ocorreu nas equações de rendimento estimadas para os empregados da lavoura da cana-de-açúcar, e para os empregados da indústria do açúcar e do álcool considerados no conjunto.

\section{CONCLUSÕES}

A evolução dos indicadores socioeconômicos da lavoura canavieira mostrou-se positiva ao longo do tempo, com destaque para a região Centro-Sul e para o estado de São Paulo. A aplicação efetiva da legislação trabalhista teve o impacto positivo de reduzir o trabalho infantil, e propiciar melhorias nas condições de trabalho, incluindo o aumento da formalização. Também a grande exposição do Brasil no comércio externo e as retaliações de seus principais competidores provavelmente induziram as empresas a terem maior preocupação com as questões sociais. Em relação à escolaridade, embora destaque-se que houve uma evolução positiva no

\footnotetext{
${ }^{18}$ Os valores encontrados para os coeficientes de determinação $\mathrm{R}^{2}$, conforme variaram-se os anos de estudo do efeito limiar foram: para 9 anos, $\mathrm{R}^{2}=0,584780$; para 10 anos, $\mathrm{R}^{2}=0,597327$; para 11 anos, $\mathrm{R}^{2}=0,597206$. Conforme indicado na literatura, escolheu-se a equação de coeficiente de determinação mais alto.
} 
período analisado, ela ainda é bastante baixa e difere entre as regiões produtoras, sendo pior na região Norte-Nordeste.

Verificou-se que atuação dos sindicatos difere entre os estados: no estado de São Paulo, seguido pelo estado de Pernambuco, conclui-se que sua importância dos mesmos nas negociações salariais e nos acordos coletivos é maior. Por sua vez, no estado de Alagoas, conclui-se que, apesar da existência da representação profissional, a grande informalidade do mercado de trabalho agrícola, aliado a um quadro técnico menos preparado, reduzem a eficiência da representação dos trabalhadores neste estado.

Quanto aos modelos estimados, que visam identificar as variáveis que explicam o rendimento dos empregados da lavoura da cana-de-açúcar, e para os empregados da indústria do açúcar e do álcool considerados conjuntamente, conclui-se que em todos os modelos os coeficientes das seguintes variáveis foram significativos e com os sinais esperados: (i) sexo, as mulheres tendiam ganhar menos; (ii) região: os empregados da região Norte-Nordeste tendiam a ganhar menos; (iii) escolaridade: empregados com níveis maiores de escolaridade tendiam a ganhar mais, (iv) efeito limiar da escolaridade: captado em todos os modelos.

Conforme destacado pela literatura, o efeito da escolaridade sobre os rendimentos foi também captado nas regressões estimadas. Considerando-se o baixo nível de escolaridade dos empregados do setor, destaca-se a necessidade de estratégias privadas e políticas públicas visando a alfabetização e aumento da escolaridade dos empregados da lavoura canavieira. Ademais, a mecanização crescente no estado de São Paulo, além de exigir uma mão de obra com escolaridade mais alta e qualificada para as novas atividades mecanizadas, reduzirá a demanda pelos trabalhadores de baixa escolaridade, incluindo a grande parcela da analfabetos existentes no setor. Como proporção importante de cortadores de cana neste estado é proveniente dos estados mais pobres da região Norte-Nordeste, salienta-se o impacto negativo nas regiões de origem destes empregados de baixa escolaridade.

O efeito da filiação ao sindicato também foi captado nos modelos estimados: o sinal do coeficiente da variável filiação à sindicato foi positivo e significativo tanto para a lavoura da cana-de-açúcar como para a indústria do açúcar e do álcool consideradas em conjunto. Para a lavoura canavieira o efeito percentual de ser sindicalizado sobre o rendimento foi de $22,38 \%$,e para a indústria considerada no conjunto, o efeito foi de $8,77 \%$.

Dessa forma, sugere-se uma maior atenção ao funcionamento do sistema sindical, de forma a fortalecer a representação profissional, dada sua influência positiva sobre os rendimentos dos empregados e em suas condições de trabalho.

\section{REFERÊNCIAS BIBLIOGRÁFICAS}

ARBACHE, J.S. (2002) Unions and the labor market in Brazil. Arbache (July 2001). IPEA-World Bank Brazil Jobs Report. Available at SSRN: <http://ssrn.com/abstract=308564 or DOI: $10.2139 /$ ssrn.308564>.

BARROS, R.P.; MENDONÇA, R.S.P. (2008) Os determinantes da desigualdade no Brasil. IPEA: Rio 
de Janeiro, jul. 1995. (Texto para discussão, 377). Disponível em: <http://www. ipea.gov.br/pub/ td/td_377.pdf>. Acesso em: 10 maio 2008.

CACCIAMALI, M.C. (2005). Política social e reforma laboral no Brasil. Os desafios da reforma sindical. In: Encontro de Economia Política, Campinas, 2005.Versão mais completa Política social e reforma laboral no Brasil. Os desafios dos sindicatos sob o governo Lula Publicado na Revista de Relaciones Laborales, n. 7, Universidad de La República del Uruguay, 2005.

CARVALHO, C.P. (2007) Economia Popular. Uma via de modernização para Alagoas. 2a. Ed. Maceió: EDUFAL.

EISENBERG, P.L. (1977) Modernização sem mudança. Campinas: Paz e Terra, Unicamp, 194 p.

FERREIRA, R.M.F. (1983) A política e as políticas das relações de trabalho. 1983. Tese (Doutorado em Ciência Política). Faculdade de Filosofia, Letras e Ciências Humanas. de Universidade de São Paulo, São Paulo.

HOFFMANN, R.; NEY, M.G. (2004) Desigualdade, escolaridade e rendimentos na agricultura, indústria e serviços, de 1992 a 2002. Economia e Sociedade, Campinas, v.13, n.2 (23), Jul/Dez

HOFFMANN, R.; SIMÃO, R.C.S. (2005) Determinantes do rendimento das pessoas ocupadas em Minas Gerais em 2000: o limiar no efeito da escolaridade e as diferenças entre mesorregiões. Nova Economia, V.15, N.2, Maio-Agosto

SIMÃO, R.C.S. (2009) Distribuição da renda e diferenças regionais no Estado de São Paulo. Tese (Doutor em Desenvolvimento Econômico) - Instituto de Economia, Universidade Estadual de Campinas, Campinas, 2009.

HOFFMANN, R. (2007) O rendimento das pessoas ocupadas na agroindústria canavieira do Brasil. In: Macedo, I.C. A energia da cana-de-açúcar. Doze estudos sobre a agroindústria da cana-de-açúcar no Brasil e a sua sustentabilidade. São Paulo: Berlendis \& Vertecchia: UNICA - União da Agroindústria Canavieira do Estado de São Paulo, 2007, cap 12, p.220-p.225

HORN, C.H. Poder de barganha dos sindicatos e negociações coletivas na indústria dório Grande do Sul, 1979-1995. Revista de Economia Política, v.28, n.3, (111), pp510-529, julho-setembro, 2008

KASSOUF, A.L. (1997) Retornos à escolaridade e ao treinamento nos setores urbano e rural do Brasil. Revista de Economia e Sociologia Rural, Brasília, v. 35, n. 2, p. 59-76, abr./jun. 1997.

LANGONI, C.G. (2005) Distribuição da renda e desenvolvimento econômico do Brasil. Rio de Janeiro: Editora FGV, $3^{\text {a }} \mathrm{Ed}, 280 \mathrm{p}$.

MISHEL, L.; WALTERS, M. (2003) How unions help all workers. Economic Policy Institute. EPI Briefing Paper, n.143. AugusT, Washington, DC. http://epinet.org

MORAES, M.A.F.D. (2000) A desregulamentação do setor sucralcooleiro do Brasil. Americana: Caminho Editorial.

MORAES, M.A.F.D.; PESSINI, M. (2004) Analysis of the labor market of the brazilian sugar alcohol sector. Washington: WORLD BANK, 77p.

MORAES, M.A.F.D. (2007a) O mercado de trabalho da agroindústria canavieira: desafios e oportunidades. Economia Aplicada, São Paulo, v.11, N.4, p.605-619. Outubro-Dezembro

MORAES, M.A.F.D. (2007b) Indicadores do mercado de trabalho do Sistema Agroindustrial da Cana-de-Açúcar do Brasil no período 1992-2005. Estudos Econômicos. São Paulo, v.37, N.4, p.875902, Outubro-Dezembro.

OLIVEIRA, F.C.R. de. (2009) Ocupação, emprego e remuneração na cana-de-açúcar e em outras atividades agropecuárias no Brasil, de 1992 a 2007. 167 p. Dissertação (Mestrado em Economia Aplicada) - Escola Superior de Agricultura “Luiz de Queiroz”, Universidade de São Paulo, Piracicaba, 2009.

PESQUISA NACIONAL POR AMOSTRA DE DOMICÍlIOS. PNAD. CD-ROM. Rio de Janeiro, RJ. Vários anos

PRADO, C.J. (1990) História econômica do Brasil. São Paulo: Brasiliense, 38º edição, 364p. 


\section{APÊNDICE 1}

Equações de rendimentos estimadas para empregados da lavoura da cana-deaçúcar, para os anos de 1993 e 2006

\begin{tabular}{|c|c|c|c|c|}
\hline \multirow{2}{*}{ Variável } & \multicolumn{2}{|c|}{1993} & \multicolumn{2}{|c|}{2006} \\
\hline & Coeficiente & $\begin{array}{l}\text { Efeito \% no } \\
\text { rendimento }\end{array}$ & Coeficiente & $\begin{array}{l}\text { Efeito \% no } \\
\text { rendimento }\end{array}$ \\
\hline Constante & $\begin{array}{c}5,4943 \\
12,60^{*}\end{array}$ & & $\begin{array}{r}2,9180 \\
10,19 *\end{array}$ & \\
\hline Pessoas do sexo feminino & $\begin{array}{r}-0,2868 \\
-5,42^{*}\end{array}$ & $-24,93$ & $\begin{array}{r}-0,2324 \\
-4,48^{*}\end{array}$ & $-20,74$ \\
\hline Idade/10 & $\begin{array}{r}0,4351 \\
6,20^{*}\end{array}$ & & $\begin{array}{r}0,2965 \\
5,01^{*}\end{array}$ & \\
\hline (Idade/10)2 & $\begin{array}{r}-0,0478 \\
-5,10^{*}\end{array}$ & & $\begin{array}{r}-0,0340 \\
-4,65^{*}\end{array}$ & \\
\hline Escolaridade $<=10$ anos & $\begin{array}{r}0,0616 \\
6,68^{*}\end{array}$ & 6,35 & $\begin{array}{l}0,0230 \\
4,15^{*}\end{array}$ & 2,33 \\
\hline $\begin{array}{l}\text { Adicional para Escolaridade } \\
>10 \text { anos }\end{array}$ & $\begin{array}{r}0,1933 \\
3,22^{*}\end{array}$ & 29,03 & $\begin{array}{r}0,0924 \\
2,98^{*}\end{array}$ & 12,24 \\
\hline Log (horas trab/semana) & $\begin{array}{l}0,7943 \\
7,04^{*}\end{array}$ & & $\begin{array}{r}0,6768 \\
9,52^{*}\end{array}$ & \\
\hline Filiação Sindicato & $\begin{array}{r}0,1333 \\
3,15^{*}\end{array}$ & 14,26 & $\begin{array}{r}0,2026 \\
7,10^{*}\end{array}$ & 22,46 \\
\hline Região Norte-Nordeste & $\begin{array}{l}-0,5780 \\
-13,87^{*}\end{array}$ & $-43,90$ & $\begin{array}{l}-0,4279 \\
-13,92^{*}\end{array}$ & $-34,81$ \\
\hline Número de observações & 1.062 & & 962 & \\
\hline R2 & 0,364411 & & 0,403795 & \\
\hline Teste F & $75,47^{*}$ & & $80,68^{*}$ & \\
\hline
\end{tabular}

Fonte: elaborado a partir de dados das PNADs de 1993 e 2006

* Coeficientes estatisticamente significativos ao nível de $1 \%$ 


\section{APÊNDICE 2}

Equações de rendimentos estimadas para empregados da indústria do açúcar e do álcool. 2006

\begin{tabular}{|c|c|c|}
\hline \multirow{2}{*}{$\begin{array}{l}\text { Variável } \\
\text { Explanatória }\end{array}$} & \multicolumn{2}{|c|}{ Açúcar e Álcool } \\
\hline & Coeficiente & Efeito \% no rendimento \\
\hline Constante & $\begin{array}{r}3,8950 \\
6,11^{*}\end{array}$ & \\
\hline Pessoas do sexo feminino & $\begin{array}{c}-0,3588 \\
-3,68^{*}\end{array}$ & $-30,15$ \\
\hline Idade/10 & $\begin{array}{r}0,4042 \\
3,33^{*}\end{array}$ & \\
\hline (Idade/10)2 & $\begin{array}{l}-0,0246 \\
-1,60 \text { ns }\end{array}$ & \\
\hline Escolaridade $<=10$ anos & $\begin{array}{r}0,0371 \\
4,47^{*}\end{array}$ & 3,78 \\
\hline Escolaridade $>10$ anos & $\begin{array}{r}0,1815 \\
9,13^{*}\end{array}$ & 24,43 \\
\hline Filiação Sindicato & $\begin{array}{c}0,0773 \\
1,65^{* * *}\end{array}$ & 8,03 \\
\hline Região Norte-Nordeste & $\begin{array}{c}-0,3588 \\
-7,54^{*}\end{array}$ & $-30,15$ \\
\hline Número de observações & 406 & \\
\hline R2 & 0,597327 & \\
\hline F Modelo & 73,61 & \\
\hline
\end{tabular}

Fonte: elaborado a partir de dados das PNADs de 2006

* Coeficientes estatisticamente significativos ao nível de $1 \%$

*** Coeficientes estatisticamente significativos ao nível de $10 \%$

${ }^{\text {ns }}$ Coeficiente não estatisticamente significativo 